Original Research Article

\title{
Evaluation of awareness about obesity among general public visiting the tertiary care hospital
}

\author{
Umamageswari Arunachalam $^{1}$, Simhadri V. S. D. N. A. Nagesh ${ }^{2}$, \\ S. Priestly Vivekkumar ${ }^{1}$, Abinaya V.S. ${ }^{1}$
}

${ }^{1}$ Department of Pharmacology, Tagore Medical College and Hospital, Rathinamangalam, Vandalur, Chennai, Tamil Nadu, India

${ }^{2}$ Department of Pharmacology, Shri Ram Murti Smarak Institute of medical Sciences, Bareilly, Uttar Pradesh, India

Received: 11 October 2019

Revised: 11 November 2019

Accepted: 12 November 2019

\section{*Correspondence to: \\ Dr. Umamageswari \\ Arunachalam, \\ Email: leeuma6@gmail.com}

Copyright: () the author(s), publisher and licensee Medip Academy. This is an openaccess article distributed under the terms of the Creative Commons Attribution NonCommercial License, which permits unrestricted noncommercial use, distribution, and reproduction in any medium, provided the original work is properly cited.

\begin{abstract}
Background: Obesity is one of the fastest growing threats of health and wellbeing for both developed and developing countries. The aim of the study was to evaluate the awareness about obesity among general public.

Methods: After obtaining institutional ethics committee approval and written informed consent from the participants, anthropometric measures like height, weight, hip and waist circumference for computing body mass index and waist hip ratio were taken. Using portable bioelectric impedance analyzer body fat percentage was measured. A validated questionnaire including socio demographic details and questions evaluating the awareness about obesity were given to the participants.

Results: Totally 100 participants were evaluated, of which majority being female. Mean height of the male and female participants was 164 and $152 \mathrm{~cm}$ respectively. Similarly, mean weight was found to be 72 and $65 \mathrm{~kg}$. Based on the body mass index only $19 \%$ participants were within normal range, remaining $81 \%$ were overweight and obese. Percent body fat and waist hip ratio was found to be increased in both sexes. Majority of the participants were aware that obesity is associated with health problems but most of them were unaware how it is measured and the dietary foods to be taken to reduce obesity. However $64 \%$ participants think that obesity can reduce the life expectancy of the individual.

Conclusions: Majority of the participants were obese and overweight while awareness about preventive measures was still lacking. Hence health care personnel need to take greater effort to educate and inform people about the implications.
\end{abstract}

Keywords: Obesity, Body mass index, Percent body fat, Waist hip ratio

\section{INTRODUCTION}

Obesity is defined as an abnormal growth of the adipose tissue due to enlargement of fat cell size or an increase in fat cell number or a combination of both. ${ }^{1}$ It is a true epidemic and public health crisis which is at the fifth leading risk of global deaths. In India, the noncommunicable risk factor survey shows high prevalence of overweight in all age groups except in 15-24 years. From the recent World Health Organization (WHO) global estimates, the worldwide prevalence of obesity nearly tripled between 1975 and $2016 .^{2}$
The etiology of obesity is multifactorial, involving complex interactions among the genetic background, hormones and different social and environmental factors, such as sedentary lifestyle and unhealthy dietary habits. ${ }^{3}$ It is clearly associated with type 2 diabetes mellitus, hypertension, hyperlipidemia, cancer, osteoarthritis particularly of the knee, cardiovascular disease, obstructive sleep apnea and asthma. One of the most important consequences of rapid increase in prevalence of obesity is reflecting in dramatic increase in the prevalence of diabetes. ${ }^{4}$ It has been observed that obesity can reduce the life expectancy at the age of 40 years by 
up to 7 years for non-smokers and 13 years for smokers. Since accumulation of fat results from discrepancy between energy consumption and energy expenditure, moderate to high intensity physical activity is necessary to maximize weight loss and prevent significant weight gain. In recent times, handful of genes influence obesity has been identified which can also influence fat distribution and poses risk of metabolic consequences. ${ }^{5}$ WHO classified obesity based on body mass index (BMI) is the gold standard indicator for identifying patients at risk of medical complications and weight status. ${ }^{6}$ Abdominal fat mass measured by waist circumference or waist hip ratio is the single most important determinant associated with the development of insulin resistance and cardiovascular diseases. ${ }^{7}$ Another assessment of obesity based on the true fat mass is percent body fat (PBF), which can be precisely measured by instruments like bioelectrical impedance analysis, magnetic resonance imaging, computed tomography and dual energy X-ray absorptiometry being quite expensive. ${ }^{8}$ Due to significant variability in the body composition, various parameters should be used to classify obesity.

For good health, the quality and food sources of various nutrients matters more than their relative quantity in the diet. Higher protein diets seem to have some advantages for weight loss in providing more satiety, greater thermic effect and improved body composition. ${ }^{9}$ Federal guidelines on physical activity recommend at least 150 minutes per week of moderate aerobic activity. To lose weight, or to maintain weight loss, activities need to be 300 minutes per week, however for strengthening of muscles, activities like push-ups or sit-ups for at least twice a week should be done. ${ }^{10}$ Optimum level of physical activity along with life style modifications like low calorie diet and behavioural therapy are important for prevention of weight gain and development of obesity. Pharmacotherapy and bariatric surgery are few treatment modalities opted based on the individual's BMI, presence or absence of co morbid conditions. ${ }^{5}$

Since obesity and its related complications emerged as a major global health concern, this study was designed to evaluate the awareness about obesity among general public belonging to southern suburbs of Chennai.

\section{METHODS}

The study was a cross-sectional, questionnaire based conducted among the patients and their attendees visiting Tagore Medical College and Hospital, Chennai. By convenient sampling, 100 participants of both sexes were included in the study. Irrespective of their obesity status, age group of the participant between 18 to 65 years were included. Seriously ill, bed ridden patients and pregnant women were excluded.

After obtaining the institutional ethics committee approval the study was commenced. The participants were informed about the study and after obtaining written informed consent their anthropometric measures like height, weight, waist circumference and hip circumference were measured. Well trained staffs were involved to measure for all 100 participants so as to avoid subject error and the instruments used was standardised to avoid instrument error before start of the study. To avoid measurement error, standard protocol was followed to measure each parameter. Height was measured with the subject standing in an erect position against a vertical scale of portable stadiometer and with the head positioned so that the top of the external auditory meatus was in level with the inferior margin of the bony orbit. Body weight was measured with the subject standing motionless on the weighing scale with feet $15 \mathrm{~cm}$ apart, and weight equally distributed on each leg. Waist circumference was measured at the midpoint between lower border of the rib cage and the iliac crest. Similarly, hip circumference was measured around the widest portion of the buttocks. PBF was measured using a commercially available portable device (HBF-306, Omron Health Care Co., Kyoto, Japan) that incorporated a bioelectric impedance analyzer as per the standard protocol. BMI was computed by using the formulae weight $(\mathrm{kg}) /$ height $\left(\mathrm{m}^{2}\right)$. A validated pretested questionnaire on socio demographic status and questions to assess the awareness about various aspects of obesity was administered. Completely filled questionnaires were taken for data analysis. Data was analysed using Sigma graph pad prism version-5 and Microsoft Excel 2007.

\section{RESULTS}

A total of 100 questionnaires and the anthropometric measurements of the participants were collected and assessed. Among them, $48 \%$ were males and $52 \%$ were females. Almost 56\% of participants were between 25-45 years. Regarding the level of education, $33 \%$ reached till primary level of which $10 \%$ were males and $23 \%$ were females. $43 \%$ participants finished their graduation, of which $26 \%$ were males and $17 \%$ were females.

Average height of the male participants was found to be $164 \mathrm{~cm}$ and for female participants was $152 \mathrm{~cm}$. The average weight of the male and female participants was $72 \mathrm{~kg}$ and $65 \mathrm{~kg}$ respectively. Based on the BMI cut off values $\left(\mathrm{kg} / \mathrm{m}^{2}\right), 19 \%$ of the participants were within normal range. Whereas $20 \%$ participants were found to be overweight. Overall $20 \%$ belong to class 1 obesity while $21 \%$ belong to class 2 obesity in which surprisingly $17 \%$ were females and only 4 were males. Similarly out of $20 \%$ participants belonging to class 3 obesity, $19 \%$ were females and $1 \%$ was male. The average PBF for males and females were 26 and 27 respectively. As per WHO cut off points, the risk of metabolic complications are substantially increased if the waist hip ratio is greater or equal to 0.90 in men and greater or equal to 0.85 in females. Among $48 \%$ male participants, waist hip ratio was found to be greater or equal to 0.9 in $37 \%$ and lesser or equal to 0.9 in $11 \%$. Whereas among $52 \%$ female participants, $25 \%$ were lesser or equal to 0.85 and $27 \%$ were greater or equal to 0.85 (Table 1 ). 
Table 1: Demographic details and anthropometric measures of male and female participants.

\begin{tabular}{|c|c|c|c|}
\hline Parameters & \multicolumn{3}{|l|}{ No. of participants } \\
\hline \multicolumn{4}{|l|}{ Gender } \\
\hline Male & \multicolumn{3}{|l|}{48} \\
\hline Female & \multicolumn{3}{|l|}{52} \\
\hline Age (in years) & Male & \multicolumn{2}{|c|}{ Female } \\
\hline $18-24$ & 4 & \multicolumn{2}{|l|}{13} \\
\hline $25-45$ & 34 & \multicolumn{2}{|l|}{22} \\
\hline $46-65$ & 10 & \multicolumn{2}{|l|}{17} \\
\hline \multicolumn{4}{|l|}{ Education } \\
\hline Primary & 10 & \multicolumn{2}{|l|}{23} \\
\hline High secondary & 12 & \multicolumn{2}{|l|}{12} \\
\hline Degree & $\begin{array}{l}26 \\
164+689\end{array}$ & \multicolumn{2}{|l|}{17} \\
\hline Height $(\mathrm{cm})($ mean \pm SD) & \multirow{2}{*}{$\begin{array}{l}164 \pm 6.89 \\
72+1082\end{array}$} & \multicolumn{2}{|c|}{$152 \pm 5.80$} \\
\hline Weight $(\mathrm{cm})($ mean \pm SD $)$ & & \multicolumn{2}{|c|}{$65 \pm 13.13$} \\
\hline \multicolumn{3}{|l|}{ BMI } & \\
\hline Normal (18.5-24.9) & $\begin{array}{l}15 \\
15\end{array}$ & \multicolumn{2}{|l|}{4} \\
\hline Overweight (25-29.9) & $\begin{array}{l}15 \\
13\end{array}$ & \multicolumn{2}{|l|}{5} \\
\hline Obese $1(30-34.9)$ & 13 & \multirow{2}{*}{\multicolumn{2}{|c|}{$\begin{array}{l}7 \\
17\end{array}$}} \\
\hline Obese 2 (35-39.9) & 4 & & 17 \\
\hline Obese $3(>40)$ & 1 & \multirow{2}{*}{\multicolumn{2}{|c|}{$\begin{array}{l}19 \\
27.38 \pm 5.49\end{array}$}} \\
\hline $\mathrm{PBF}(\mathrm{mean} \pm \mathrm{SD})$ & $26.68 \pm 4.19$ & & \\
\hline \multirow{2}{*}{ Waist hip ratio } & $<0.90$ & $<0.85$ & $>0.85$ \\
\hline & 11 & 25 & 27 \\
\hline
\end{tabular}

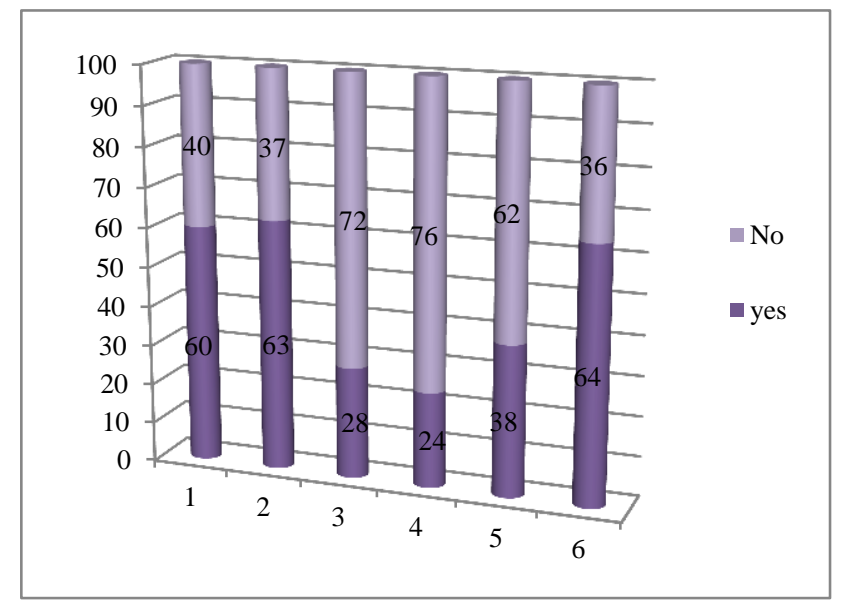

Figure 1: Questions regarding awareness about obesity, expressed in no. of participants.

1- Do you think obesity is a disease; 2 - Does obesity associated with serious medical problem; 3 - Do you know how obesity is measured; 4- Are you aware about the treatment given to the obese patients; 5- Are you aware of dietary foods to be taken to reduce obesity; 6- Can obesity reduce the life span of the individual.

On evaluating the awareness about obesity, $60 \%$ of the participants think that obesity is a disease whereas $40 \%$ of them disagree. On question about whether obesity is associated with serious medical problems $63 \%$ of the participants were aware but $37 \%$ of them were not aware. Only $28 \%$ participants knew how obesity is measured, remaining $72 \%$ did not know. Similarly $76 \%$ participants were unaware about the treatment given to obese patients whereas only $24 \%$ knew about it. About $62 \%$ participants were not aware what are the dietary foods to be taken to reduce obesity and 38 of them were aware. 64 participants think that obesity can reduce the life span of the individual, whereas remaining 36 were not aware (Figure 1).

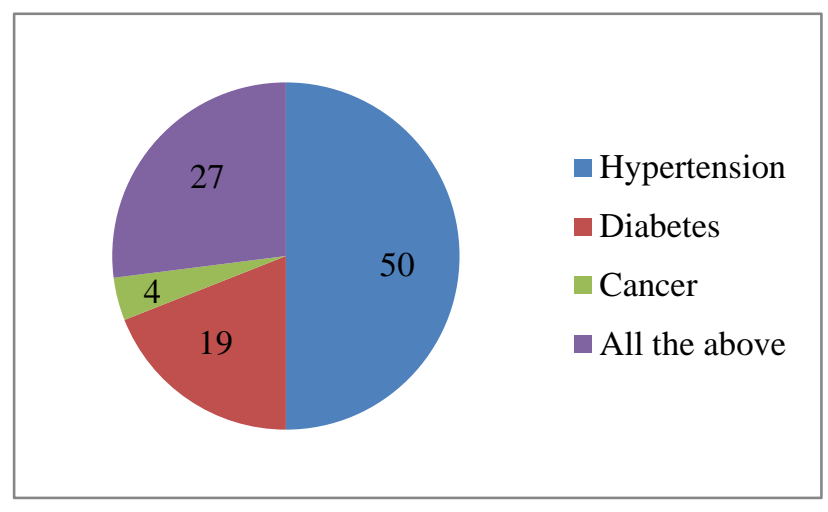

Figure 2: Among the disease given, obesity can lead to, expressed in no. of participants.

Exactly $50 \%$ participants feel that obesity can lead to hypertension and only $4 \%$ feel it might lead to cancer (Figure 2). When asked about the causative factor for obesity, $40 \%$ participants responded saying improper diet whereas $21 \%$ responded by saying physical inactivity (Figure 3). Regarding, preventive measures they would like to follow, $58 \%$ of the participants preferred to go walking and $27 \%$ of them wished to work out in gym (Figure 4). 


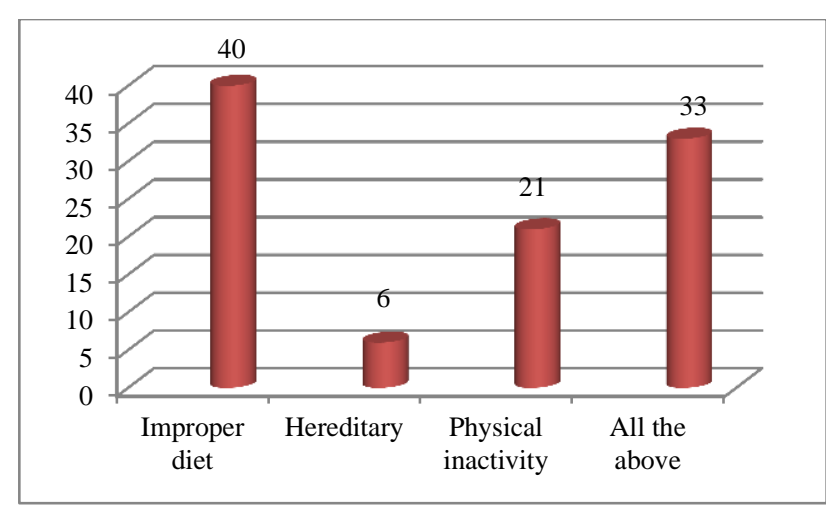

Figure 3: According to you, which of the following would be the causative factor of obesity, expressed in no. of participants.

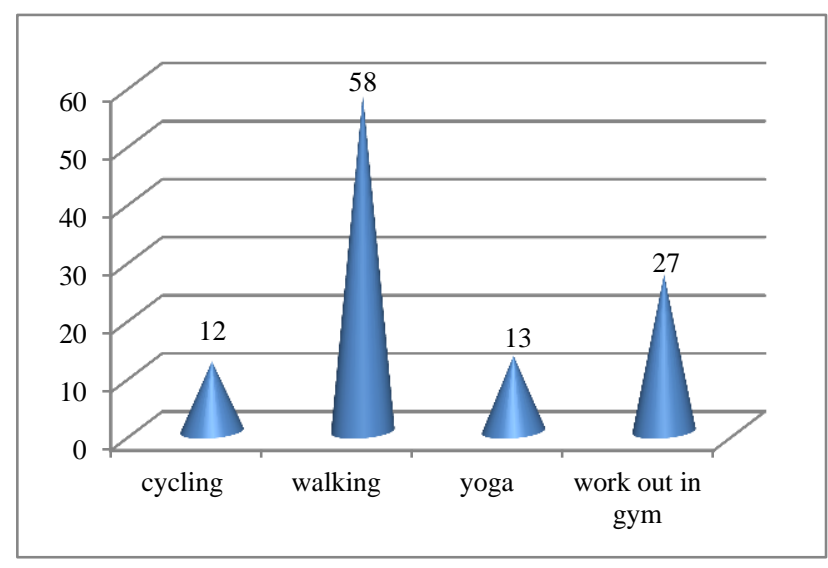

Figure 4: Which of the following preventive measure you would like to follow, expressed in no. of participants.

\section{DISCUSSION}

Obesity is defined by the WHO as "abnormal or excessive fat accumulation that may impair health". It is a gateway to many serious diseases, including diabetes, cancer, cardiovascular disorders and joint problems.

In our study, participants lack awareness about measurement of obesity, various treatments given to obese patients and dietary foods to be taken. However participants were aware that obesity can reduce the life expectancy of the individual. Similar result was noticed in the study conducted among young individuals, in which $72 \%$ felt that obese persons have a shorter lifespan (by atleast 7 years) when compare to non-obese individuals. ${ }^{11}$ In the present study when enquired about the disease obesity can lead to, majority of the participants felt hypertension followed by diabetes and only $4 \%$ responded cancer. However, in various other studies obesity was identified as one of the risk factors for development of breast cancer, in addition it was found to be a causal factor for cancers of the small intestine, colon and gallbladder. ${ }^{12}$
BMI is routinely used as a common indicator to quantify adiposity for all ages. Based on the BMI, majority of the participants $(89 \%)$ in our study were overweight and obese. However, BMI is not able to differentiate between fat and fat-free mass and hence need to be defined using different methods like PBF. It is widely claimed that a PBF greater than $25 \%$ for men and $35 \%$ for women are the criteria for diagnosing obesity and it has been shown to be associated with metabolic dysregulation, regardless of body weight. In our study, based on PBF, $30 \%$ of male participants and $14 \%$ of the female participants were obese. ${ }^{8}$ Whereas high PBF with low BMI pattern was seen in a study conducted among Asian-American women and they concluded that they might be escape detection for obesity-related disease if BMI is the sole measure that estimates body composition. ${ }^{13}$ Other anthropometric measures for abdominal obesity are waist circumference and waist hip ratio which are strong and consistent predictors for non-communicable diseases such as type 2 diabetes mellitus and cardiovascular disease. A study among Chinese population demonstrated that, waist circumference was found to be the best measurement of obesity whereas waist hip ratio could be used as an alternative indicator for obesity. ${ }^{14}$ In our study, based on the waist hip ratio cut-off points, $64 \%$ participants were at substantially increased risk of metabolic complications. Similar result of $65 \%$ of the participants above the cut-off points was seen in a study conducted among sub-urban population of Karachi. ${ }^{6}$

Further in our study, participants preferred physical activity followed by yoga as preventive measure to be followed. Hence, development and implementation of obesity preventive measures should focus on factors contributing to obesity, barriers to lifestyle change at personal, environmental and socioeconomic levels, and should actively involve different levels of stakeholders. ${ }^{3}$ A wide range of policy areas that could influence the food environment include, taxes on food and nonalcoholic beverages, restricting marketing and advertising bans of unhealthy foods, implementation of food and nutrition labelling, which are need to be carefully designed to achieve their intended effects.

\section{CONCLUSION}

As majority of the participants were still lacking in various aspects of obesity health care personnel should play a greater role in motivating and educating about the consequences of obesity though prevention and reduction of overweight and obesity ultimately depend on individual lifestyle changes.

\section{ACKNOWLEDGEMENTS}

My sincere thanks to the Management of Tagore Medical College and Hospital, Chennai for their constant support and encouragement. I extend my thanks to our former Medical Superintendent Dr. Thirunarayanan for providing portable bioelectric impedance analyzer and 
pamphlets depicting pictures on various healthy and junk foods and health risks of obesity. Last but not least, my heartfelt thanks to the study participants for sparing their valuable time in providing the information for the successful completion of the study.

Funding: No funding sources Conflict of interest: None declared

Ethical approval: The study was approved by the Institutional Ethics Committee

\section{REFERENCES}

1. Park K. Epidemiology of chronic non communicable disease and conditions. In: Park's Textbook of Preventative and Social Medicine. 24th ed. India:M/s Banarsidas Bhanot; 2017: 415-417.

2. World Health Organization. Key facts: Obesity and overweight. Available at: https://www.who.int/newsroom/fact-sheets/detail/obesity-and-overweight. Accessed on 2 September 2019.

3. Chan RSM, Jean Woo. Prevention of overweight and obesity: how effective is the current public health approach. Int $\mathbf{J}$ Environ Res Public Health. 2010;7:765-783.

4. Pignone M, Salazar R. Disease prevention and health promotion. In: McPhee SJ, Papadakis MA. Current Medical Diagnosis and Treatment.15 th ed. New York, NY: Mc Graw Hill; 2011: 14-15.

5. Shand AG, Wilding JPH. Nutritional factors in disease. In: Ralston SH, Penman ID, Strachan MWJ, Hobson RP. Davidson's Principles and Practice of Medicine. 23rd ed. United Kingdom, UK: Elsevier; 2018: 698-702.

6. Amin F, Fatima SS, Islam N, Gilani AH. Prevalence of obesity and overweight, its clinical markers and associated factors in a high risk South-Asian population. BioMed Central. 2015;2(16):1-11.

7. Kushner RF. Evaluation and management of Obesity. In: Longo DL, Kasper D, Jameson L, Fauci AS,
Hauser SL, loscalzo J. Harrison's Principles of Internal Medicine.18th ed. New York, NY: Mc Graw Hill; 2012: 629-632.

8. Ho-Pham LT, Lai TQ, Nguyen MTT, Nguyen TV. Relationship between Body Mass Index and Percent Body Fat in Vietnamese: Implications for the Diagnosis of Obesity. PLoS One. 2015;10(5):1-13.

9. Harvard TH. Obesity Prevention Sources. Available at: https://www.hsph.harvard.edu/obesity-preventionsource/obesity-causes/diet-and-weight. Accessed on 25 August 2019.

10. National Institute of Diabetes and Digestive and kidney Disease. Health Risks of Being Overweight. Available at: https://www.niddk.nih.gov/healthinformation/weight-management/health-risksoverweight. Accessed on 16 August 2019.

11. Delasalle AGM, Arunachalam, Menezes SA. Awareness of Complications of Obesity in Young Individuals. IOSR J Dent Med Sci. 2016;15(8):6-8.

12. Shrivastava S, Shrivastava P, Ramasamy J. Assessment of knowledge about obesity among students in a medical college in Kancheepuram district, Tamil Nadu. Prog Health Sci. 2013;3(1):5460 .

13. Carpenter CL, Yan E, Chen S, Hong K, Arechiga A, Kim WS, et al. Body fat and body-mass index among a multi-ethnic sample of college-age men and women. J Obes. 2013;2013:790654.

14. Yanga F, Lv JH, Lei SF, Chena XD. Receiveroperating characteristic analyses of body mass index, waist circumference and waist-to-hip ratio for obesity: Screening in young adults in central south of China. Clin Nut. 2006;25:1030-9.

Cite this article as: Arunachalam U, Nagesh SVSDNA, Vivekkumar SP, Abinaya VS. Evaluation of awareness about obesity among general public visiting the tertiary care hospital. Int J Basic Clin Pharmacol 2019;8:2724-8. 